Observational Study. Clinical Reviews in Allergy \& Immunology. 2009; 38 (2-3): 90-96.

Disclosure of Interests: Ripa Akter: None declared, Walter P Maksymowych Grant/research support from: AbbVie, Pfizer, Janssen, Novartis, Consultant for: AbbVie, Eli Lilly, Boehringer, Galapagos, Janssen, Novartis, Pfizer and UCB Pharma; Chief Medical Officer for Canadian Research and Education Arthritis, Liam Martin: None declared, David Hogan: None declared

DOI: 10.1136/annrheumdis-2019-eular.4547

\section{SAT0132 LONG-TERM SAFETY, IMMUNOGENICITY AND EFFICACY IN RANDOMIZED, DOUBLE-BLIND, AND OPEN-LABEL EXTENSION STUDIES COMPARING FKB327, AN ADALIMUMAB BIOSIMILAR, WITH THE ADALIMUMAB REFERENCE PRODUCT IN PATIENTS WITH ACTIVE RHEUMATOID ARTHRITIS}

Rieke Alten ${ }^{1}$, Mark C. Genovese ${ }^{2}$, Arai $^{3}$, Rafael Muniz ${ }^{4}$, Herbert Kellner ${ }^{5}$. ${ }^{1}$ University Medicine Berlin, Berlin, Germany; ${ }^{2}$ Stanford University Medical Center, Palo Alto, CA, United States of America; ${ }^{3}$ Fujifilm Kyowa Kirin Biologics Co., Ltd., Tokyo, Japan; ${ }^{4}$ Mylan Inc., Canonsburg, PA, United States of America; ${ }^{5}$ Specialist Practice in Rheumatology and Gastroenterology, Munich, Germany

Background: FKB327 is a biosimilar of adalimumab reference product (RP). Studies with adalimumab biosimilars have shown no increase in safety signals or immunogenicity versus RPs studied at 52 weeks.

Objectives: To study the long-term safety, immunogenicity and efficacy of FKB327 compared with Adalimumab RP in a randomized double blind (DB) phase 3 study in patients (pts) with active rheumatoid arthritis (RA) inadequately controlled with methotrexate (MTX) and in a subsequent randomized, open-label extension (OLE) study with treatment switching assessed long-term safety, efficacy, PK, and immunogenicity.

Methods: Pts aged $\geq 18$ years with moderate-to-severe, active RA (2010 ACR/EULAR criteria) for $\geq 3$ months and receiving a stable dose of MTX were randomized $1: 1$ to FKB327 or RP (40 mg subcutaneously [SQ]) every other week with MTX. In the OLE study, pts who completed the DB study with clinical response and no serious adverse events (AEs) were rerandomized in a $2: 1$ ratio to FKB327 or RP. All pts received FKB327 through week 76 (Period 2). The primary end point was safety; the secondary end point was efficacy. Pooled data for up to 2 years were analyzed to assess long-term safety. Incidence rates of treatmentemergent AEs were adjusted by overall exposure to enable safety comparison of FKB327 and RP.

Results: Of 728 pts in the DB study, 645 were enrolled in the OLE; of those, 572 and 515 pts completed periods 1 and 2, respectively. Safety results from the pooled data were comparable between treatment sequences. Mean serum drug concentrations appeared to be in steady-state in all treatment sequences in Period 1 and comparable among sequences in Period 2. The proportion of pts with positive antidrug antibody (ADA) status in Period 1 was comparable between treatment sequences, and the majority of patients with positive ADA status had neutralizing activity. The mean proportion of patients achieving an ACR20 response remained stable between studies and was similar for all treatment sequences.

Table. Summary of Efficacy \& Safety End Points at Week 30 (Period 2): Full Analysis Set

\begin{tabular}{|c|c|c|c|c|}
\hline & $\begin{array}{c}\text { F-F-F } \\
\mathrm{N}=216\end{array}$ & $\begin{array}{c}F-H-F \\
N=108\end{array}$ & $\begin{array}{c}\text { H-F-F } \\
\mathrm{N}=108\end{array}$ & $\begin{array}{l}\mathrm{H}-\mathrm{H}-\mathrm{F} \\
\mathrm{N}=213\end{array}$ \\
\hline \multicolumn{5}{|c|}{ ACR20 response rate } \\
\hline $\mathrm{n}$ & 185 & 98 & 92 & 189 \\
\hline Responders, n (\%) & $154(83.2)$ & $82(83.7)$ & $79(85.9)$ & $158(83.6)$ \\
\hline $95 \% \mathrm{Cl}$ & $77.1-88.3$ & $74.8-90.4$ & $77.0-92.3$ & $77.5,88.6$ \\
\hline \multicolumn{5}{|c|}{ ACR50 response rate } \\
\hline $\mathrm{n}$ & 185 & 98 & 92 & 189 \\
\hline Responders (\%) & $112(60.5)$ & $57(58.2)$ & $50(54.3)$ & $113(59.8)$ \\
\hline $95 \% \mathrm{Cl}$ & $53.1-67.6$ & $47.8-68.1$ & $43.6-64.8$ & $52.4,66.8$ \\
\hline \multicolumn{5}{|c|}{ DAS28-CRP response rate } \\
\hline $\mathrm{n}$ & 183 & 99 & 92 & 189 \\
\hline Mean (SD) & $3.04(1.237)$ & $3.28(1.385)$ & $3.20(1.247)$ & $3.13(1.239$ \\
\hline Range & $1.2-7.1$ & $1.2-7.1$ & $1.3-6.3$ & $1.2,7.4$ \\
\hline \multicolumn{5}{|l|}{ ADA status } \\
\hline Total & 187 & 100 & 93 & 190 \\
\hline Positive & $97(51.9)$ & $61(61.0)$ & $42(45.2)$ & $98(51.6)$ \\
\hline
\end{tabular}

adalimumab; SD, standard deviation.
Conclusion: The safety, immunogenicity, and efficacy of FKB327 were maintained over long-term treatment and after switching between the biosimilar and RP.

Disclosure of Interests: Rieke Alten Grant/research support from: BristolMyers Squibb, Speakers bureau: Bristol-Myers Squibb, Mark C. Genovese Grant/research support from: Sanofi/Genzyme, Genentech/Roche, RPharm, Consultant for: Sanofi/Genzyme, Genentech/Roche, RPharm, Yasumasa Arai Employee of: I am an employee of Fujifilm Kyowa Kirin Biologics. Rafael Muniz Shareholder of: Employee of Mylan, Consultant for: Employee of Mylan, Employee of: Employee of Mylan, Herbert Kellner Grant/research support from: Roche, Consultant for: Roche DOI: 10.1136/annrheumdis-2019-eular.972

\section{SAT0133 TREATMENT PATTERNS, PERSISTENCE, AND DURABILITY IN RHEUMATOID ARTHRITIS PATIENTS WITH INADEQUATE RESPONSE TO BIOLOGIC DISEASE-MODIFYING ANTI-RHEUMATIC DRUGS (BDMARDS)}

Robin K. Dore ${ }^{1}$, Jenya Antonova ${ }^{2}$, Chakkarin Burudpakdee ${ }^{3}$, Xin Wang ${ }^{4}$, Burak Ozbay ${ }^{2}$, Mark C. Genovese ${ }^{5}$. ${ }^{1}$ Private practice, Tustin, United States of America; ${ }^{2}$ Gilead Sciences, Foster City, United States of America; ${ }^{3}$ IQVIA, Falls Church, United States of America; ${ }^{4} I Q V I A$, Plymouth meeting, United States of America; ${ }^{5}$ Stanford University, Stanford, United States of America

Background: EULAR and ACR recommend bDMARDs, as monotherapy or in combination with methotrexate, in patients whose rheumatoid arthritis (RA) remains active despite methotrexate use. ${ }^{1}$ Treatment options for bDMARD inadequate response (IR) patients vary. Understanding the realworld treatment patterns and treatment duration in bDMARD IR patients may help identify the most suitable next treatment.

Objectives: We studied treatment patterns, treatment persistence, and treatment durability in bDMARD IR patients who switched to another treatment regimen.

Methods: In US health plan claims data, this study selected adult RA bDMARD patients: those with $\geq 2$ RA diagnoses $\geq 30$ days apart, who newly initiated a bDMARD (1/1/2012 - 3/31/2017; baseline) and then switched to another bDMARD or JAKi (index date, ID). All patients had continuous $\geq 1$-year enrollment before and after ID. Patient characteristics were evaluated at baseline; treatment patterns, persistence, and durability (duration) were evaluated during pre- and post-index periods. KaplanMeier curves were used to evaluate treatment persistence.

Results: Among 105,039 patients who were initiated on bDMARDs, 19,085 (18\%) demonstrated IR; among those, 4,656 met all the selection criteria: median age 54 years, 22\% male, 17\% from Northeast, 26\% Midwest, $42 \%$ South, $15 \%$ West.

At baseline, $26 \%$ used tumor necrosis factor inhibitors (TNFi) monotherapy and $64 \%$ used TNFi in combination with conventional synthetic DMARD (csDMARD). Baseline median treatment duration was 8.3 months overall, including 5.8 months for monotherapy and 9.4 months for combination therapy

Upon switch, $46 \%$ of patients used monotherapy (28\% TNFi, $11 \%$ other bDMARD, $7 \%$ janus kinase inhibitors [JAKi]), and 54\% used bDMARD in combination with csDMARD (37\% TNFi + csDMARD, $12 \%$ other bDMARD

Table. Post-switch treatment patterns, duration, and 12-month persistence.

\begin{tabular}{|c|c|c|c|}
\hline & $\begin{array}{l}\text { Patient } \\
\text { allocation }\end{array}$ & $\begin{array}{l}\text { Median treatment } \\
\text { duration (months) }\end{array}$ & $\begin{array}{c}\text { 12-month } \\
\text { persistence }\end{array}$ \\
\hline All patients $(\mathrm{N}=4,656)$ & $100 \%$ & 9.5 & $48 \%$ \\
\hline $\begin{array}{l}\text { Index monotherapy } \\
(\mathrm{N}=2,149)^{*}\end{array}$ & $46 \%$ & 5.8 & $33 \%$ \\
\hline TNFi $(\mathrm{N}=1,305)^{\star *}$ & $28 \%$ & 5.1 & $31 \%$ \\
\hline other bDMARDs $(\mathrm{N}=521)^{\star \star}$ & $11 \%$ & 6.9 & $35 \%$ \\
\hline JAKi $(N=323)^{\star \star}$ & $7 \%$ & 6.7 & $41 \%$ \\
\hline $\begin{array}{l}\text { Index combination therapy } \\
(\mathrm{N}=2,507)^{\star}\end{array}$ & $54 \%$ & 13.1 & $60 \%$ \\
\hline$\underset{* \star \star}{\operatorname{csDMARD}}+\mathrm{TNFi}(\mathrm{N}=1,740)$ & $37 \%$ & 12.3 & $57 \%$ \\
\hline $\begin{array}{l}\text { csDMARD + other } \\
\text { bDMARDs }(\mathrm{N}=569)^{\star * *}\end{array}$ & $12 \%$ & 15.1 & $69 \%$ \\
\hline $\begin{array}{l}\operatorname{csDMARD}+\text { JAKi }(\mathrm{N}=198) \\
\star \star \star\end{array}$ & $4 \%$ & 14.3 & $67 \%$ \\
\hline
\end{tabular}

